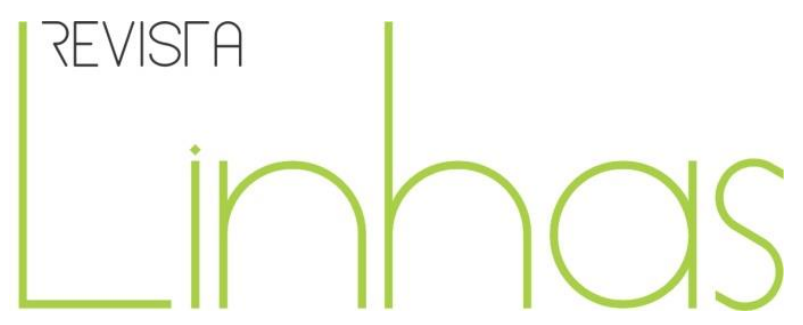

\title{
Material didático para a educação a distância: um estudo de caso ${ }^{1}$
}

\begin{abstract}
Resumo
Esta pesquisa teve como objetivo analisar os materiais didáticos produzidos para o ensino técnico na modalidade a distância da Rede e-Tec Brasil CEFET-MG, baseando-se na proposta de metodologia recursiva de Oliveira, Costa e Moreira (2001). Optou-se pela pesquisa científica de natureza qualitativa. Quanto ao tipo de pesquisa, ela foi exploratória e descritiva. Em relação a procedimentos técnicos, adotaram-se o estudo de caso e a pesquisa bibliográfica. Para coleta de dados, foram utilizadas a observação do ambiente virtual de aprendizagem e questionários aplicados aos sujeitos envolvidos no primeiro módulo do curso técnico, professores e alunos. Os resultados sinalizaram que os professores não adotam um modelo metodológico para produção de materiais didáticos, apesar de utilizarem algumas práticas consideradas pela literatura como boas práticas para produção de materiais didáticos para EaD. Dessa forma, verificou-se a necessidade da adoção de diretrizes metodológicas para os cursos e a organização e o desenvolvimento de formação de professores.
\end{abstract}

Palavras-chave: Educação a Distância - Meios Auxiliares. Materiais Didáticos. Ensino Técnico.

\section{Márcia Gorett Ribeiro Grossi}

Centro Federal de Educação

Tecnológica de Minas Gerais CEFET-MG - Minas Gerais/Brasil marciagrossi@terra.com.br

\section{José Wilson Costa}

Pontifícia Universidade Católica de Minas Gerais - PUC-MG Minas Gerais/Brasil jwcosta01@gmail.com

\section{Elaine Ribeiro Silva}

Centro Federal de Educação Tecnológica de Minas Gerais CEFET-MG - Minas Gerais/Brasil laninha@gmail.com

\footnotetext{
Para citar este artigo:

GROSSI, Márcia Gorett Ribeiro; COSTA, José Wilson; SILVA, Elaine Ribeiro. Material didático para a educação a distância: um estudo de caso. Revista Linhas. Florianópolis, v. 18, n. 36, p. 325-346, jan./abr. 2017.
}

DOI: $\mathbf{1 0 . 5 9 6 5 / 1 9 8 4 7 2 3 8 1 8 3 6 2 0 1 7 3 2 5}$

http://dx.doi.org/10.5965/1984723818362017325

\footnotetext{
${ }^{1}$ Os estudos que subsidiaram esta pesquisa tiveram auxílio financeiro da Fundação de Amparo à Pesquisa do Estado de Minas Gerais (FAPEMIG).
} 


\title{
Educational materials for distance learning: a case study
}

\begin{abstract}
This research aimed to analyze the educational materials produced for technical education in the distance learning mode of the e-Tec Brasil CEFETMG network, based on the proposal of recursive methodology of Oliveira, Costa and Moreira (2001). We opted for the scientific research of qualitative nature. Regarding the type of research, it was exploratory and descriptive. In relation to technical procedures, the case study and the literature review were adopted. For data collection, we used the observation of the virtual learning environment and questionnaires to the subjects involved in the first module of the technical course, teachers and students. The results showed that teachers do not adopt methodological models to produce teaching materials, despite using some practices considered by the literature as good practice in the production of learning materials for distance education. The need to follow methodological guidelines for the courses, and for the organization and development of teachers training programs was thus verified.
\end{abstract}

Keywords: Distance Education - Auxiliary Resources. Teaching Materials. Technical Education. 


\section{Introdução}

O avanço cada vez maior das Tecnologias de Informação e Comunicação (TIC) tem contribuído na transformação da educação, principalmente na Educação a distância, que segundo Formiga (2009, p. 39), "está intrinsicamente ligada às Tecnologias da Informação e Comunicação (TIC) por se constituir setor altamente dinâmico e pródigo em inovação".

Essa modalidade de ensino tem ampliado suas vagas rapidamente. O número de cursos oferecidos a distância aumenta a cada ano. Em 2012, houve um aumento de 3,4\% em relação a 2011, já em 2013 o aumento foi de 26,9\% no número de cursos autorizados; $13,2 \%$ no número de cursos livres e $55 \%$ no número de cursos corporativos. (CENSO EAD.BR, 2013/2014). Ainda de acordo com dados do Censo EAD.BR, a evolução das matrículas nos cursos a distância evoluiu para 59\% de 2013 para 2014, e há uma projeção de crescimento de matrículas para 82\% no ano de 2015.

A Educação a Distância (EaD) foi formalizada como modalidade de ensino através da Lei $n^{\circ}$ 9.394, de 20 de dezembro de 1996, Lei de Diretrizes e Bases (LDB), que em seu artigo 80 regulamenta que "o Poder Público incentivará o desenvolvimento e a veiculação de programas de ensino a distância, em todos os níveis e modalidades de ensino, e de educação continuada." Posteriormente, houve a regulamentação do Decreto $\mathrm{n}^{\circ}$ 2.494, de 10 de fevereiro de 1998, que estabelece o conceito da EaD como "forma de ensino que possibilita a autoaprendizagem com a mediação de recursos didáticos, sistematicamente organizados, apresentados em diferentes suportes de informação, usados isoladamente ou combinados e veiculados pelos diversos meios de comunicação".

Mais tarde, 19 de dezembro de 2005, foi criado o Decreto $n^{\circ} 5.622$, que caracteriza a EaD como uma modalidade educacional na qual a mediação didático-pedagógica nos processos de ensino e aprendizagem ocorre com o uso das TIC, com estudantes e professores desenvolvendo atividades educativas em lugares ou tempos diferentes.

Então, percebe-se que as ações de governo na promoção da EaD têm passado pela legislação e por projetos de ensino superior e médio, sendo que esse último é o foco de interesse dessa pesquisa, uma vez que os cursos a distância estudados nessa pesquisa são cursos técnicos integrados ao médio. Então, em relação ao ensino médio, o Decreto 
$n^{\circ} 7.589$, de 26 de outubro de 2011, estabeleceu a criação da Rede e-Tec Brasil, visando o desenvolvimento da educação profissional e técnica na modalidade de educação a distância, para ampliação e oferta democratizadora ao acesso a cursos técnicos de nível médio, públicos e gratuitos para o interior do país e para a periferia das áreas metropolitanas.

Nesse contexto, o tema desta pesquisa teve como locus os cursos técnicos a distância da Rede e-Tec Brasil ofertados no Estado de Minas Gerais pelo Centro Federal de Educação Tecnológica de Minas Gerais (CEFET-MG) e, como objeto, as metodologias de produção de material didático multimídia para EaD, baseados na metodologia recursiva de Oliveira, Costa e Moreira (2001), que tem como fundamentação teórica a concepção interacionista e construtivista do conhecimento de Piaget (PIAGET, 1978; GARCIA, 2002).

Diante dessa realidade, o objetivo dessa pesquisa foi analisar os materiais didáticos produzidos para o ensino técnico na modalidade a distância da Rede e-Tec Brasil CEFET-MG, baseando-se na proposta acima descrita. Vale ressaltar que esses materiais foram elaborados pela equipe da Rede e-Tec do CEFET-MG.

A escolha deste tema se fundamenta em perceber que, embora os cursos técnicos de nível médio a distância da Rede e-Tec Brasil sigam orientações e diretrizes curriculares que têm como aportes legais diversas legislações federais, as estratégias de ensino e materiais didáticos são propostas no âmbito dos projetos pedagógicos das instituições ofertantes dos cursos, e ainda não existe uma metodologia estruturada para produção de material didático multimídia.

\section{Referencial teórico \\ Educação a Distância e a Rede e-Tec Brasil}

Pode se dizer que, a modalidade EaD exige um perfil diferenciado de estudante; a aprendizagem transformou-se pela necessidade de um perfil mais ativo. Os alunos, em sua maioria, não são receptores passivos de conteúdos selecionados pelos seus professores. Eles participam da construção do seu conhecimento. Segundo Santos apud Vidal (2002), a EaD utiliza as TIC que permitem trabalhar com uma quantidade grande de 
dados e com agilidade considerável, promovendo a autoaprendizagem, possibilitando um desenvolvimento pessoal constante dos indivíduos e concedendo-lhes maior autonomia.

Thompson (2002) ajuda no entendimento da modalidade de EaD, ao listar suas características:

- Há uma separação entre professor e aluno no tempo ou no lugar, ou em ambos;

- A aprendizagem é acreditada ou certificada por uma instituição ou entidade, e é diferente da aprendizagem pelo esforço próprio, sem o reconhecimento oficial de uma instituição de ensino;

- Utilizam-se meios mistos, como a inclusão de rádio, documentos impressos, transmissão de televisão, vídeos e áudios, aprendizagem baseada em computador e telecomunicações. Antes de serem utilizados os materiais empregados nos cursos, normalmente, são pré-testados e validados.

- A comunicação bidirecional, que permite a alunos e professores interagir, ao contrário de uma recepção passiva de sinais transmitidos. A comunicação pode ser síncrona ou assíncrona;

- Há a possibilidade de encontros presenciais, para tutoriais, interação alunoaluno, estudo numa biblioteca e sessões em laboratório ou práticas;

- Permite o uso de processos industrializados, ou seja, em operações de ensino à distância em grande escala, o trabalho é dividido e as tarefas são atribuídas a pessoal diverso que trabalha em conjunto nas equipes de desenvolvimentos dos cursos.

Essas características permitem que a EaD possa utilizar métodos e formatos mais livres de trabalho, que abrangem a distribuição de experiências, aperfeiçoa recursos que reduzem significativamente custos de formação, permitindo aliar a aprendizagem com a atividade profissional e a vida familiar e possibilitando ao aluno escolher o método de aprendizagem que melhor se adapta à sua maneira e capacidades. Na EaD, professores e alunos envolvidos participam ativamente, por isso requer metodologias e materiais didáticos específicos para ela. 
Essa modalidade de ensino possibilita difundir conhecimento para diversas localidades, por isso, pode-se dizer que a EaD possui um forte caráter democratizador do saber, capaz de expandir e interiorizar cursos que dificilmente chegariam à modalidade presencial em regiões afastadas das grandes metrópoles. Porém, é fundamental esclarecer que sozinha a EaD não democratiza o saber. Para que isso ocorra é necessária uma política pública que garanta o acesso de todos a essa modalidade de ensino.

Dessa forma, o Decreto $n^{\circ}$ 6.301, de 12 de dezembro de 2007, instituiu "no âmbito do Ministério da Educação, o Sistema Escola Técnica Aberta do Brasil - e-Tec Brasil, com vistas ao desenvolvimento da educação profissional técnica na modalidade de Educação a Distância com a finalidade de ampliar a oferta e democratizar o acesso a cursos técnicos de nível médio, públicos e gratuitos no País" (BRASIL, 2007, online). Contudo, esse sistema sofreu mudanças por meio do Decreto $n^{\circ} 7.589$, de 26 de outubro de 2011. Esse Decreto institui atualmente como Rede e-Tec Brasil, o que antes era definido como Sistema Escola Técnica Aberta do Brasil - e-Tec Brasil. Para cumprir com as suas finalidades, o Decreto estabeleceu os seguintes objetivos:

I- estimular a oferta da educação profissional e tecnológica, na modalidade a distância, em rede nacional;

II - expandir e democratizar a oferta da educação profissional e tecnológica, especialmente para o interior do País e para a periferia das áreas metropolitanas;

III-permitir a capacitação profissional inicial e continuada, preferencialmente para os estudantes matriculados e para os egressos do ensino médio, bem como para a educação de jovens e adultos;

IV - contribuir para o ingresso, permanência e conclusão do ensino médio por jovens e adultos;

$\checkmark$-permitir às instituições públicas de ensino o desenvolvimento de projetos de pesquisa e de metodologias educacionais em educação a distância na área de formação inicial e continuada de docentes para a educação profissional e tecnológica;

$\mathrm{VI}$ - promover o desenvolvimento de projetos de produção de materiais pedagógicos e educacionais para a formação inicial e continuada de docentes para a educação profissional e tecnológica;

VII - promover junto às instituições públicas de ensino o desenvolvimento de projetos de produção de materiais pedagógicos e educacionais para estudantes da educação profissional e tecnológica; e

VIII-permitir o desenvolvimento de cursos de formação inicial e continuada de docentes, gestores e técnicos administrativos da educação profissional e tecnológica, na modalidade de educação a distância. (BRASIL, 2011, online) 
E, considerando a necessidade de consolidação dos cursos de Educação Profissional Técnica de Nível Médio e a caracterização de sua identidade em relação às demais ofertas, a Resolução n ${ }^{\circ}$ 3, de 9 de julho de 2008, instituiu o Catálogo Nacional dos Cursos Técnicos de Nível Médio, elaborado pela Secretaria de Educação Profissional e Tecnológica do Ministério de Educação. Os cursos ofertados pela Rede e-Tec Brasil são desenvolvidos de acordo com o Catálogo Nacional de Cursos Técnicos (BRASIL, 2011), documento que orienta e estabelece as condições de oferta de cursos técnicos no país.

No caso do CEFET-MG, são ofertados três cursos técnicos nas modalidades concomitante e subsequente por meio da modalidade EaD: Informática para Internet, com a carga horária de 1260 horas e 480 horas de estágio curricular; Meio Ambiente, com 1092 horas e 480 horas de estágio e, Eletroeletrônica com 1050 horas e 480 horas de estágio. Cada um dos cursos possui uma duração de 24 meses, distribuídos em quatro módulos. Esses cursos possuem quatro polos em quatro cidades do Estado de Minas Gerais: Campo Belo, Curvelo, Nepomuceno e Timóteo.

Nos cursos do e-Tec Brasil CEFET-MG, o trabalho dos professores é orientado pela coordenação pedagógica e pelos coordenadores de curso, porém não há um profissional (design instrucional) que acompanhe o trabalho de produção dos materiais didáticos e apresentação no Ambiente Virtual de Aprendizagem. Os coordenadores de curso e professores visitam os polos para aulas presenciais e atividades de laboratório assistidas. Porém, percebe-se que tem sido um desafio constante para os profissionais que atuam na EaD encontrar as melhores metodologias que se adequem aos seus cursos.

\section{Metodologia Recursiva}

A metodologia recursiva proposta por de Oliveira, Costa e Moreira (2001) tem

como fundamentação teórica a concepção interacionista e construtivista do conhecimento de Piaget (PIAGET, 1978; GARCIA, 2002), enfatizando a coerência com os fundamentos pedagógicos, referindo-se aos conhecimentos prévios, que dizem respeito à necessidade de se verificar se o aluno apresenta os conhecimentos julgados básicos para que ele possa aprender o conteúdo trabalhado. 
A partir dessa análise, são oferecidos caminhos para aqueles que ainda não apresentam esse conhecimento e caminhos alternativos para os que o apresentam, quer ao nível de uma aprendizagem real, quer ao nível de sua Zona de Desenvolvimento Proximal (ZDP), que refere-se ao caminho que o indivíduo vai percorrer para desenvolver funções que estão em processo de amadurecimento e que se tornarão funções consolidadas, estabelecidas no seu nível de desenvolvimento real.

Os alunos são impelidos a construir os conceitos teóricos inerentes ao conteúdo que está sendo trabalhado, por meio de um raciocínio lógico dedutivo provocado pela reflexão sobre a experiência que vivenciam. Oliveira, Costa e Moreira (2001), consideram que os alunos são expostos a uma interação constante com o material didático, de tal forma que as respostas possíveis de serem avaliadas apontem o nível de compreensão que o aluno tem do conteúdo em pauta, remetam a um tratamento do acerto ou do erro ali contidos e evidenciem a ausência de compreensão do aluno em relação a algum prérequisito do conteúdo que está sendo trabalhado.

Esse modelo de metodologia representa um paralelismo entre as diversas atividades que ocorrem simultaneamente e se encontram em contínua avaliação. Esta proposta "permite um retorno àqueles níveis já percorridos e possibilita reajustes e aberturas para novas construções ao longo de sua progressão. De acordo com Oliveira, Costa e Moreira (2001, p. 66) “[...] Este modelo se caracteriza por movimentos de avanço no desenvolvimento de Software Educativo (SE) através de diferentes atividades que o constituem". Pode-se perceber que o processo de construção de SE é registrado e avaliado constantemente. Existe uma correspondência entre as diversas atividades, requerendo uma integração entre elas. Vale ressaltar que essa metodologia foi proposta para orientar o processo de desenvolvimento de SE, porém pode-se considerar que possibilita adequada referência para produção de materiais didáticos para a educação a distância.

Assim, os autores desse artigo definiram critérios, a partir da relação de critérios construídos na metodologia recursiva (desenvolvidos para análise de software educativo), para análise dos materiais didáticos utilizados nas disciplinas dos cursos do eTec Brasil CEFET-MG. Chegou-se a 12 critérios: 
1- Análise de conhecimentos prévios: necessidade de verificar se o aluno apresenta os conhecimentos julgados básicos para que ele possa aprender o conteúdo trabalhado nas disciplinas.

2 - Escolha do conteúdo: diz respeito à maneira como um conteúdo trabalhado na disciplina é introduzido no processo de ensino e aprendizagem.

3 - Identificação de conceitos estruturantes: refere-se à forma de explicitação dos conceitos principais que constituem o conteúdo a ser trabalhado nas disciplinas, relacionado ao desenvolvimento de esquemas de pensamento que possibilitem ao aluno a reorganização progressiva dos novos conhecimentos.

4 - Desenvolvimento de cronograma: produção gráfica do calendário das aulas, contemplando as datas das principais atividades relacionadas às disciplinas.

5 - Sequência de conteúdo: está relacionado à maneira como os conteúdos são organizados e apresentados no ambiente de exibição Modular Object-Oriented Dynamic Learning Environment (MOODLE) da disciplina.

6 - Planejamento de Layout: planejamento da forma como os conteúdos serão visualmente apresentados na área de exibição das disciplinas.

7 - Desenvolvimento de Layout: estruturação dos conteúdos na área de apresentação das disciplinas; abrange a distribuição adequada de textos, imagens, áudios, atividades e outros.

8 - Implementação de material didático: produção do material didático utilizado nas disciplinas dos cursos do e-Tec Brasil CEFET-MG.

9 - Desenvolvimento da documentação dos materiais didáticos: constitui-se na definição de instruções com o intuito de deixar claro ao aluno qual o objetivo educacional de cada atividade apresentada na disciplina.

10 - Utilização do material didático: relacionado ao uso do material didático, ou seja, se o material produzido e proposto para as disciplinas está sendo utilizado nos cursos.

11 - Avaliação do material didático: constante avaliação do material apresentado no que concerne à necessidade de validar se o conteúdo está atendendo às necessidades aos alunos.

12 - Manutenção do material didático: ajustes frequentes nos materiais didáticos apresentados para que os mesmos possam garantir seu melhor aproveitamento. 
É pertinente ressaltar que, na EaD, o material didático tem o papel de mediador da interação dos alunos com os conteúdos, fazendo uma interface fundamental entre os alunos e os conteúdos. Desta maneira, Neder (2005) afirma que o material didático em EaD deverá garantir a adequação ao grupo social a que se destina, garantindo os princípios norteadores do Projeto Político Pedagógico, sendo problematizador e impulsionando para o trabalho investigativo que estimule habilidades reflexivas e de ação dos sujeitos.

Em se tratando de características elementares na criação do material didático para a EaD, Belisário (2003) propõe elementos estruturais (Macro e Micro) e torna evidentes suas características e sua importância para reforçar o processo de ensino e aprendizagem do aluno. Do ponto de vista macro, o autor ressalta a característica Interativa, relacionada à forma na qual a leitura é entremeada pela realização de exercícios interativos. Também cita a característica Sequencial, que é a forma adequada a uma revisão total de texto, após o estudo interativo e, por fim, descreve a característica Seletiva, que é a forma apropriada ao esclarecimento de dúvidas específicas sobre partes do texto ou conceitos emitidos no mesmo. (BELISÁRIO, 2003).

\section{Os caminhos da pesquisa}

Optou-se pela pesquisa científica de natureza qualitativa. Quanto ao tipo de pesquisa, ela foi exploratória e descritiva. Em relação a procedimentos técnicos, adotouse o estudo de caso e a pesquisa bibliográfica.

A pesquisa foi realizada, no segundo semestre de 2014 e primeiro de 2015, junto aos professores e alunos dos cursos técnicos a distância do CEFET-MG. No que concerne a coleta de dados, foi feito o levantamento através dos instrumentos de coletas: a observação do ambiente virtual de aprendizagem e questionários aplicados aos professores e alunos do primeiro módulo dos cursos analisados (Informática para Internet, Meio Ambiente e Eletroeletrônica). Esse módulo foi escolhido porque era o que estava sendo ofertado durante o desenvolvimento dessa pesquisa.

A pesquisa foi dividida em três etapas: 
Primeira etapa: Identificar e analisar os materiais didáticos produzidos nos cursos selecionados, por meio de busca no ambiente virtual de aprendizagem destes cursos, sempre à luz da metodologia recursiva proposta por Oliveira, Costa e Moreira (2001).

Segunda etapa: Verificar, sob a perspectiva dos professores, questões relativas aos métodos utilizados na produção e uso de materiais didáticos produzidos nos cursos analisados. Para isso, foi usado como ferramenta de coleta de dados, um questionário aplicado a todos os professores (14) dos cursos do e-Tec Brasil CEFET-MG, disponibilizado pelo Google e acessado pela plataforma MOODLE O questionário foi elaborado com questões fundamentadas na metodologia recursiva e, contemplava as categorias: “Conteúdos das Disciplinas” (forma de organização e apresentação dos conteúdos); "Interatividade" (interação de aluno-conteúdo, aluno-tutor, aluno-professor, alunoaluno); "Recursos Motivacionais" (recursos utilizados nos conteúdos, que possibilitaram estímulo e motivação aos alunos nos seus estudos) e, "Adequação das Atividades Pedagógicas" (verificação da conformidade do conhecimento científico apresentado com a escolha dos autores dos materiais).

Terceira etapa: Verificar se os materiais didáticos existentes nos cursos analisados atendiam aos alunos dos cursos. Para isso, foi utilizado como ferramenta de coleta de dados, um questionário que foi aplicado a todos aos alunos (150) que estavam efetivamente participando dos cursos do e-Tec Brasil CEFET-MG, disponibilizado pelo Google e acessado pela plataforma MOODLE. O questionário foi elaborado com questões que contemplavam as mesmas categorias do questionário dos professores.

\section{Apresentação e análise dos resultados Da primeira etapa}

Os materiais didáticos foram identificados através de uma busca no Moodle Tool Guide for Teachers (MOODLE), que é o ambiente virtual de aprendizagem dos cursos a distância do CEFET-MG. Os dados referentes ao uso desses recursos nas disciplinas dos três cursos foram organizados nos Quadros 1, 2 e 3. Assim, os recursos relacionados para análise foram definidos tendo como referência o guia de ferramentas do MOODLE. 
Quadro 1 - Recursos utilizados nas Disciplinas do Curso Técnico em Eletroeletrônica

\begin{tabular}{|l|l|l|l|l|}
\hline \multicolumn{2}{|c|}{ Recursos } & \multicolumn{5}{c|}{ Curso de Eletroeletrônica } \\
\cline { 2 - 5 } & $\begin{array}{l}\text { Português } \\
\text { Instrumental }\end{array}$ & $\begin{array}{l}\text { Matemática } \\
\text { Aplicada I }\end{array}$ & Módulo \\
\hline Vídeo & Sim & Não & Sim & $\begin{array}{l}\text { Fundamentos de } \\
\text { Eletroeletrônica }\end{array}$ \\
\hline Questionário & Sim & Sim & Não & Não \\
\hline Fórum & Não & Sim & Não & Não \\
\hline $\begin{array}{l}\text { Apresentaçã } \\
\text { o }\end{array}$ & Sim & Não & Não & Não \\
\hline Glossário & Não & Não & Não & Não \\
\hline Texto & Sim & Sim & Sim & Não \\
\hline
\end{tabular}

Fonte: Elaborado pelos autores com base nos dados do AVA.

Pelo Quadro 1, pode-se observar que o recurso utilizado comum a todas as disciplinas foi texto e, o recurso que não foi utilizado por nenhuma disciplina foi o glossário.

Quadro 2 - Recursos utilizados nas Disciplinas do Curso Técnico em Informática para Internet

\begin{tabular}{|c|c|c|c|c|c|}
\hline \multicolumn{6}{|c|}{ Curso de Informática para Internet } \\
\hline \multirow[b]{2}{*}{ Recursos } & \multicolumn{5}{|c|}{ Disciplinas do $1^{\circ}$ Módulo } \\
\hline & $\begin{array}{l}\text { Arquitetura de } \\
\text { Computadores }\end{array}$ & \begin{tabular}{|l|} 
Gestão \\
Organizacional e \\
Segurança do \\
Trabalho \\
\end{tabular} & $\begin{array}{l}\text { Algoritmos e } \\
\text { Lógica de } \\
\text { Programação }\end{array}$ & $\begin{array}{l}\text { Fundamentos } \\
\text { da Informática }\end{array}$ & $\begin{array}{l}\text { Redação } \\
\text { técnica }\end{array}$ \\
\hline Vídeo & Não & Sim & Sim & Não & Não \\
\hline Questionário & Sim & Não & Sim & Não & Não \\
\hline Fórum & Sim & Não & Não & Sim & Não \\
\hline Apresentação & Não & Não & Não & Não & Não \\
\hline Glossário & Não & Não & Não & Não & Não \\
\hline Texto & Sim & Sim & Sim & Sim & Sim \\
\hline
\end{tabular}

Fonte: Elaborado pelos autores com base nos dados do AVA.

De acordo com o Quadro 2, o texto também foi um recurso comum a todas elas, em seguida vídeo, questionário e fórum foram os recursos utilizados em duas disciplinas. Já apresentações e glossários foram recursos nunca explorados. 
Quadro 3 - Recursos utilizados nas Disciplinas do Curso Técnico em Meio Ambiente

\begin{tabular}{|l|l|l|l|l|l|}
\hline \multicolumn{5}{|c|}{ Recursos } & \multicolumn{5}{|c|}{ Curso de Meio Ambiente } \\
\cline { 2 - 6 } & Climatologia & $\begin{array}{l}\text { Metodologia de } \\
\text { Projetos }\end{array}$ & $\begin{array}{l}\text { Geografia e Análise } \\
\text { ambiental }\end{array}$ & $\begin{array}{l}\text { Ecologia } \\
\text { Aplicada }\end{array}$ & $\begin{array}{l}\text { Educação } \\
\text { Ambiental }\end{array}$ \\
\hline Vídeo & Sim & Não & Sim & Sim & Sim \\
\hline Questionário & Não & Não & Não & Não & Não \\
\hline Fórum & Sim & Sim & Sim & Sim & Sim \\
\hline Apresentação & Não & Não & Sim & Não & Não \\
\hline Glossário & Não & Não & Não & Não & Não \\
\hline Texto & Sim & Sim & Sim & Sim & Sim \\
\hline
\end{tabular}

Fonte: Elaborado pelos autores com base nos dados do AVA.

Pelo Quadro 3 é possível perceber que fórum e texto foram recursos comuns a todas as disciplinas. Em seguida, o vídeo, que foi utilizado em quatro disciplinas; apresentação em uma disciplina e questionário e glossário nunca foram explorados.

Após analisar os dados dos três quadros, verificou-se que os recursos apresentados podem ser considerados ferramentas tecnológicas que, de certa forma, contribuem para a aprendizagem do aluno, possibilitando, ampliando e alterando o processo de conhecimento. Segundo Levy (1987), a tecnologia não pode estar dissociada da dinâmica em que o conhecimento é desenvolvido. Porém, observou-se que não houve um padrão de utilização dos recursos. Há disciplinas que utilizam mais recursos e outras menos ou quase nenhum.

Já a Tabela 1 mostra se as disciplinas de cada curso, do e-Tec Brasil CEFET-MG, contemplam os 12 critérios definidos de acordo com a metodologia recursiva.

Tabela 1 - Análise dos Materiais Didáticos, baseada na Metodologia Recursiva

\begin{tabular}{|c|c|c|c|c|c|c|c|c|c|c|c|c|c|}
\hline \multirow[b]{2}{*}{ Cursos } & \multirow[b]{2}{*}{ Disciplinas } & \multicolumn{12}{|c|}{ Critérios } \\
\hline & & 1 & 2 & 3 & 4 & 5 & 6 & 7 & 8 & 9 & 10 & 11 & 12 \\
\hline \multirow{5}{*}{ ELE } & $\begin{array}{l}\text { Português } \\
\text { Instrumental }\end{array}$ & Não & Sim & Sim & Sim & Sim & Sim & Sim & Sim & Sim & Sim & Não & Sim \\
\hline & $\begin{array}{l}\text { Matemática } \\
\text { Aplicada }\end{array}$ & Não & Sim & Sim & Não & Sim & Sim & Sim & Sim & Sim & Sim & Não & Não \\
\hline & $\begin{array}{l}\text { Eletrônica } \\
\text { Digital } 1\end{array}$ & Não & Sim & Não & Não & Sim & Sim & Sim & Sim & Sim & Sim & Não & Não \\
\hline & $\begin{array}{l}\text { Fundamentos } \\
\text { de } \\
\text { Eletroeletrônica }\end{array}$ & Não & Sim & Não & Não & Sim & Sim & Não & Sim & Não & Sim & Não & Não \\
\hline & $\begin{array}{l}\text { Arquitetura de } \\
\text { Computadores }\end{array}$ & Não & Sim & Sim & Sim & Sim & Sim & Sim & Sim & Não & Sim & Não & Não \\
\hline
\end{tabular}




\begin{tabular}{|c|c|c|c|c|c|c|c|c|c|c|c|c|c|}
\hline \multirow[t]{4}{*}{ INF } & $\begin{array}{l}\text { Gestão } \\
\text { Organizacional } \\
\text { e Segurança do } \\
\text { Trabalho }\end{array}$ & Não & Sim & Sim & Sim & Sim & Sim & Sim & Sim & Não & Sim & Não & Não \\
\hline & $\begin{array}{l}\text { Lógica de } \\
\text { programação }\end{array}$ & Não & Sim & Sim & Sim & Sim & Sim & Sim & Sim & Não & Sim & Não & Não \\
\hline & $\begin{array}{l}\text { Fundamentos } \\
\text { de Informática }\end{array}$ & Não & Sim & Sim & Sim & Sim & Sim & Sim & Sim & Não & Sim & Não & Não \\
\hline & Redação Técnica & Não & Sim & Sim & Sim & Sim & Sim & Sim & Sim & Não & $\operatorname{Sim}$ & Não & Não \\
\hline \multirow[t]{5}{*}{ MA } & Climatologia & Não & Sim & Sim & Sim & Sim & Sim & Sim & Sim & Não & Sim & Não & Não \\
\hline & $\begin{array}{l}\text { Metodologia de } \\
\text { projetos }\end{array}$ & Não & Sim & Sim & Sim & Sim & Sim & Sim & Sim & Não & Sim & Não & Não \\
\hline & $\begin{array}{l}\text { Geografia e } \\
\text { Análise ambiental }\end{array}$ & Não & Sim & Sim & Sim & $\operatorname{Sim}$ & Sim & Não & Sim & $\operatorname{Sim}$ & $\operatorname{Sim}$ & Não & Não \\
\hline & Ecologia Aplicada & Não & Sim & Sim & Sim & Sim & Sim & Sim & Sim & Sim & Sim & Não & Não \\
\hline & $\begin{array}{l}\text { Educação } \\
\text { Ambiental }\end{array}$ & Não & Sim & Sim & Sim & Sim & Sim & Sim & Sim & Sim & Sim & Não & Não \\
\hline
\end{tabular}

Fonte: Elaborado pelos autores com base nos dados do AVA.

Os dados da tabela 1 foram levantados pelos autores desse artigo a partir da análise de cada uma das disciplinas dos cursos aqui estudados, no MOODLE, em relação ao atendimento ou não dos 12 critérios que foram criados a partir da metodologia recursiva. Vale ressaltar que esses critérios estão apresentados no referencial desse artigo. Assim, com base nos dados apresentados, pode-se verificar que seis critérios foram atendidos em todas as disciplinas dos três cursos; três critérios foram atendidos pela maioria das disciplinas dos cursos e; apenas três critérios não foram atendidos por nenhuma disciplina dos três cursos. Esse resultado indica que os cursos possuem uma coerência de metodologia entre eles e também considerável sintonia com a metodologia recursiva, apesar de não discutirem adequadamente a análise de conhecimentos prévios e os conceitos estruturantes.

\section{Da segunda etapa}

Todos os quatro professores do curso técnico em Eletroeletrônica responderam ao questionário. Já no curso técnico em Meio Ambiente, dos cinco professores, três participaram da pesquisa e, no curso técnico em Informática para Internet, todos os professores (cinco) responderam ao questionário. A compilação dos dados coletados está apresentada no Quadro 4. 
Quadro 4 - Perspectiva dos professores sobre questões relativas aos métodos utilizados na produção e uso de materiais didáticos produzidos nos cursos analisados

\begin{tabular}{|c|c|c|c|}
\hline \multirow[b]{2}{*}{$\begin{array}{c}\text { Questões } \\
\text { investigadas }\end{array}$} & \multicolumn{3}{|c|}{ Cursos } \\
\hline & Eletroeletrônica & Informática para Internet & Meio Ambiente \\
\hline $\begin{array}{l}1 \text { - Clareza na } \\
\text { apresentação } \\
\text { dos conteúdos }\end{array}$ & $\begin{array}{l}\text { Todos os professores } \\
\text { disseram ter essa } \\
\text { preocupação. }\end{array}$ & $\begin{array}{l}\text { Três professores } \\
\text { disseram ter essa } \\
\text { preocupação. }\end{array}$ & \begin{tabular}{llr} 
(a) Um & \multicolumn{2}{r}{ professor } \\
respondeu & ter & essa \\
preocupação. & & \\
\end{tabular} \\
\hline $\begin{array}{l}2 \text { - Acessos dos } \\
\text { alunos aos } \\
\text { conteúdos }\end{array}$ & $\begin{array}{l}\text { Metade dos professores } \\
\text { respondeu que } \\
\text { disponibilizou os materiais } \\
\text { de forma a facilitar o acesso } \\
\text { dos aos mesmos. }\end{array}$ & $\begin{array}{l}\text { Quatro professores } \\
\text { responderam que sempre } \\
\text { organizaram os conteúdos } \\
\text { de forma a viabilizar o acesso } \\
\text { dos alunos aos mesmos. }\end{array}$ & $\begin{array}{l}\text { Dois professores } \\
\text { responderam que sempre } \\
\text { organizaram os conteúdos } \\
\text { de forma a viabilizar o acesso } \\
\text { dos alunos aos mesmos. }\end{array}$ \\
\hline $\begin{array}{l}\text { 3- Dúvidas dos } \\
\text { alunos sobre os } \\
\text { conteúdos }\end{array}$ & $\begin{array}{l}\text { Três professores } \\
\text { responderam que sempre } \\
\text { tentam solucionar as } \\
\text { dúvidas. }\end{array}$ & $\begin{array}{l}\text { (b) Três professores } \\
\text { responderam que sempre } \\
\text { tentam solucionar as } \\
\text { dúvidas. }\end{array}$ & $\begin{array}{l}\text { Todos os professores } \\
\text { responderam que sempre } \\
\text { tentam solucionar as } \\
\text { dúvidas. }\end{array}$ \\
\hline $\begin{array}{l}\text { 4- Conhecimentos } \\
\text { básicos prévios } \\
\text { dos alunos }\end{array}$ & $\begin{array}{lr}\text { Metade dos professores } \\
\text { respondeu que sempre } \\
\text { geram } \\
\text { diagnósticas. }\end{array}$ & $\begin{array}{l}\text { Um professor respondeu que } \\
\text { sempre gera atividades } \\
\text { diagnósticas e, três, } \\
\text { raramente. }\end{array}$ & $\begin{array}{l}\text { Dois professores } \\
\text { responderam que sempre } \\
\text { geraram atividades } \\
\text { diagnósticas. }\end{array}$ \\
\hline $\begin{array}{l}5 \text { - Clareza nas } \\
\text { instruções das } \\
\text { atividades }\end{array}$ & $\begin{array}{l}\text { Todos os professores } \\
\text { responderam que sempre } \\
\text { têm essa preocupação. }\end{array}$ & $\begin{array}{l}\text { Dois professores } \\
\text { responderam que sempre } \\
\text { têm essa preocupação. }\end{array}$ & $\begin{array}{l}\text { Dois professores } \\
\text { responderam que sempre } \\
\text { têm essa preocupação. }\end{array}$ \\
\hline $\begin{array}{l}6 \text { - Interatividade } \\
\text { entre eles e os } \\
\text { alunos }\end{array}$ & $\begin{array}{l}\text { Todos afirmaram que tentam } \\
\text { promover essa } \\
\text { interatividade. }\end{array}$ & $\begin{array}{l}\text { Quatro professores disseram } \\
\text { que interagem pouco com } \\
\text { seus alunos e, um professor, } \\
\text { sempre. }\end{array}$ & $\begin{array}{l}\text { Todos afirmaram que tentam } \\
\text { promover essa } \\
\text { interatividade. }\end{array}$ \\
\hline $\begin{array}{l}7 \text { - Interatividade } \\
\text { entre alunos e } \\
\text { tutores }\end{array}$ & $\begin{array}{l}\text { Metade dos professores } \\
\text { respondeu que sim. }\end{array}$ & $\begin{array}{l}\text { Três professores } \\
\text { responderam que sim. }\end{array}$ & $\begin{array}{l}\text { Dois professores } \\
\text { responderam que sim. }\end{array}$ \\
\hline $\begin{array}{l}8 \text { - Interatividade } \\
\text { entre os alunos }\end{array}$ & $\begin{array}{l}\text { Todos afirmaram que tentam } \\
\text { promover essa } \\
\text { interatividade. }\end{array}$ & $\begin{array}{l}\text { Todos afirmaram que tentam } \\
\text { promover essa } \\
\text { interatividade. }\end{array}$ & $\begin{array}{l}\text { Dois professores } \\
\text { responderam que realizaram } \\
\text { muitas vezes. }\end{array}$ \\
\hline $\begin{array}{l}9 \text { - Recursos } \\
\text { tecnológicos fora } \\
\text { do MOODLE }\end{array}$ & $\begin{array}{l}\text { (c) Todos } \\
\text { professores responderam } \\
\text { que os recursos que mais } \\
\text { usam são imagens, textos, } \\
\text { vídeos, fóruns, chats, } \\
\text { glossários, wikis } \\
\text { questionários. }\end{array}$ & $\begin{array}{l}\text { Todos os professores } \\
\text { disseram que os recursos } \\
\text { mais usados foram imagens, } \\
\text { textos, vídeos, fóruns, } \\
\text { diagramas, chats, glossários, } \\
\text { wikis, questionário e } \\
\text { software para elaboração de } \\
\text { algoritmos. }\end{array}$ & $\begin{array}{l}\text { (d) Todos os } \\
\text { professores responderam } \\
\text { que os recursos mais usados } \\
\text { foram imagens, textos, } \\
\text { vídeos, fóruns, chats, } \\
\text { glossários, wikis } \\
\text { questionários. }\end{array}$ \\
\hline $\begin{array}{l}10 \text { - Organização } \\
\text { dos conteúdos }\end{array}$ & $\begin{array}{l}\text { Três professores } \\
\text { responderam que sempre } \\
\text { organizam os conteúdos de } \\
\text { forma a facilitar a } \\
\text { compreensão dos alunos. }\end{array}$ & $\begin{array}{l}\text { Três professores } \\
\text { responderam que sempre } \\
\text { organizam os conteúdos de } \\
\text { forma a facilitar a } \\
\text { compreensão dos alunos. }\end{array}$ & $\begin{array}{l}\text { (e) Todos os } \\
\text { professores responderam } \\
\text { que sempre organizam os } \\
\text { conteúdos de forma a } \\
\text { facilitar a compreensão dos } \\
\text { alunos. }\end{array}$ \\
\hline $\begin{array}{l}11 \text { - Quantidades } \\
\text { de recursos } \\
\text { usados em aula }\end{array}$ & $\begin{array}{l}\text { Metade dos professores } \\
\text { respondeu que os recursos } \\
\text { foram usados em uma } \\
\text { quantidade equilibrada para } \\
\text { não sobrecarregar o aluno. }\end{array}$ & $\begin{array}{l}\text { Dois professores } \\
\text { responderam que os } \\
\text { recursos sempre foram } \\
\text { usados em uma quantidade } \\
\text { equilibrada para não } \\
\text { sobrecarregar o aluno. }\end{array}$ & $\begin{array}{l}\text { Um professor respondeu } \\
\text { sempre usar tais recursos e, } \\
\text { um professor respondeu } \\
\text { utilizar poucas vezes. }\end{array}$ \\
\hline $\begin{array}{l}12 \text { - Interesse dos } \\
\text { alunos nos }\end{array}$ & $\begin{array}{l}\text { Dois professores disseram } \\
\text { que os recursos utilizados }\end{array}$ & $\begin{array}{l}\text { Três professores } \\
\text { responderam que os }\end{array}$ & $\begin{array}{l}\text { Para dois professores, os } \\
\text { recursos usados despertam }\end{array}$ \\
\hline
\end{tabular}




\begin{tabular}{|c|c|c|c|}
\hline $\begin{array}{l}\text { Recursos } \\
\text { utilizados }\end{array}$ & $\begin{array}{l}\text { despertam no aluno o } \\
\text { interesse pelos estudos. }\end{array}$ & $\begin{array}{l}\text { recursos utilizados } \\
\text { despertem no aluno o } \\
\text { interesse pelo estudo dos } \\
\text { conteúdos. }\end{array}$ & $\begin{array}{l}\text { no aluno o interesse pelo } \\
\text { estudo dos conteúdos. }\end{array}$ \\
\hline $\begin{array}{l}13 \text { - Adequação } \\
\text { das atividades } \\
\text { pedagógicas com } \\
\text { o conteúdo }\end{array}$ & $\begin{array}{l}\text { Três professores } \\
\text { responderam que as } \\
\text { atividades apresentadas aos } \\
\text { alunos são coerentes com os } \\
\text { conhecimentos } \\
\text { proporcionados pelo } \\
\text { conteúdo. }\end{array}$ & $\begin{array}{l}\text { Quatro professores } \\
\text { responderam que as } \\
\text { atividades apresentadas aos } \\
\text { alunos têm coerência em } \\
\text { relação aos conhecimentos } \\
\text { proporcionados pelo } \\
\text { conteúdo. }\end{array}$ & $\begin{array}{l}\text { (f) Todos } \\
\text { professores responderam } \\
\text { que as atividades } \\
\text { apresentadas aos alunos } \\
\text { foram coerentes com os } \\
\begin{array}{l}\text { conhecimentos } \\
\text { proporcionados } \\
\text { conteúdo. }\end{array}\end{array}$ \\
\hline $\begin{array}{l}14 \text { - Coerência } \\
\text { entre os } \\
\text { conteúdos e a } \\
\text { bibliografia }\end{array}$ & $\begin{array}{l}\text { Dois professores } \\
\text { responderam que, ao } \\
\text { apresentarem os conteúdos, } \\
\text { sempre houve conformidade } \\
\text { em relação às bibliografias. }\end{array}$ & $\begin{array}{l}\text { Quatro professores disseram } \\
\text { que, ao apresentarem os } \\
\text { conteúdos, sempre houve } \\
\text { conformidade em relação às } \\
\text { bibliografias. }\end{array}$ & $\begin{array}{l}\text { (g) Dois professores } \\
\text { responderam que, ao } \\
\text { apresentarem os conteúdos, } \\
\text { sempre houve conformidade } \\
\text { em relação às bibliografias. }\end{array}$ \\
\hline
\end{tabular}

Fonte: Elaborado pelos autores com base nas respostas dos professores dos cursos estudados.

De maneira geral, pode-se perceber que os professores (14) dos três cursos se preocupam em ajudar os alunos a atingirem um bom desempenho nas atividades desenvolvidas no MOODLE, pois os professores mostram que sempre tentam estabelecer uma sequência de conteúdos para facilitar a organização da navegabilidade do aluno no ambiente virtual de aprendizagem. Também, percebe-se que o processo motivacional apresenta considerável relevância entre os professores (sete) e, a preocupação em utilizar materiais coerentes com as bibliografias sugeridas é bastante representativa nos cursos.

Já ao analisar os dados referentes ao conteúdo das disciplinas, pode-se perceber que a uma parte considerável de professores (cinco) afirmou realizar atividades diagnósticas para verificar se os alunos possuíam conhecimentos básicos para o aprendizado do conteúdo proposto. Porém, essa informação não condiz com os dados apresentados na tabela 1, pois nela não há registros de desenvolvimento de atividades diagnósticas pelos professores.

Também em relação à categoria relativa à interatividade, pode-se observar que as informações dos professores (cinco) do curso de Informática para Internet são contrárias ao que apresenta a tabela 1, pois nenhum professor estabeleceu documentação para os materiais didáticos de sua disciplina. Em relação à interatividade por meio da criação de instruções claras e objetivas, para que os alunos realizassem as atividades propostas, 
pode-se observar que foi atendido pela maior parte dos professores (oito). Assim, essa informação ajusta-se ao que apresenta a tabela 1, no critério referente à documentação feita para os materiais didáticos das disciplinas do curso em Meio Ambiente. Além disso, a definição da linguagem, vocabulário e estruturas de frases adequadas ao nível dos alunos, também é um critério de interatividade e a maioria dos professores mostrou-se envolvida no atendimento desse critério.

\section{Da terceira etapa}

Na tabela 2 estão apresentados os dados sobre a percepção dos alunos dos cursos técnicos do e-Tec Brasil CEFET-MG sobre os materiais didáticos de seus cursos. Foram convidados todos os alunos a participarem ( 52 de eletroeletrônica, 43 de Informática para Internet e 55 de Meio Ambiente), sendo que a taxa de retorno foi de 44,23\%, 39,54\% e $27,27 \%$ respectivamente.

Tabela 2 - Percepção dos alunos sobre os materiais didáticos de seus cursos

\begin{tabular}{|c|c|c|c|c|c|c|c|c|c|}
\hline \multirow{3}{*}{$\begin{array}{c}\text { Questões } \\
\text { investigadas }\end{array}$} & \multicolumn{9}{|c|}{ Cursos } \\
\hline & \multicolumn{3}{|c|}{$\begin{array}{l}\text { Eletroeletrônica } \\
\text { (ELE) }\end{array}$} & \multicolumn{3}{|c|}{$\begin{array}{l}\text { Informática para Internet } \\
\text { (INF) }\end{array}$} & \multicolumn{3}{|c|}{$\begin{array}{c}\text { Meio Ambiente } \\
\text { (MA) }\end{array}$} \\
\hline & $\begin{array}{c}\text { Sempre } \\
(\%)\end{array}$ & $\begin{array}{c}\text { Ás vezes } \\
(\%)\end{array}$ & $\begin{array}{c}\text { Nunca } \\
(\%)\end{array}$ & $\begin{array}{c}\text { Sempre } \\
(\%)\end{array}$ & $\begin{array}{c}\text { Ás vezes } \\
(\%)\end{array}$ & $\begin{array}{c}\text { Nunca } \\
(\%)\end{array}$ & $\begin{array}{c}\text { Sempre } \\
(\%)\end{array}$ & $\begin{array}{c}\text { Ás vezes } \\
(\%)\end{array}$ & $\begin{array}{r}\text { Nunca } \\
(\%)\end{array}$ \\
\hline $\begin{array}{l}1 \text { - Clareza na } \\
\text { apresentação dos } \\
\text { conteúdos }\end{array}$ & 30,4 & 69,5 & 0 & 5,9 & 82,3 & 11,8 & 20 & 73,3 & 6,7 \\
\hline $\begin{array}{l}2 \text { - Dificuldades de } \\
\text { acesso aos } \\
\text { conteúdos }\end{array}$ & 26,1 & 73,9 & 0 & 11,8 & 88,2 & 0 & 26,7 & 73,3 & 0 \\
\hline $\begin{array}{l}3 \text { - Dúvida sobre os } \\
\text { conteúdos }\end{array}$ & 0 & 73,9 & 26,1 & 7,9 & 88,2 & 3,9 & 5,7 & 93,3 & 1 \\
\hline $\begin{array}{l}\text { 4- Possuíam } \\
\text { conhecimentos } \\
\text { básicos prévios }\end{array}$ & 13 & 78,3 & 8,7 & 11,8 & 76,5 & 11,8 & 0 & 93,4 & 6,7 \\
\hline $\begin{array}{l}5 \text { - Clareza nas ins- } \\
\text { truções das } \\
\text { atividades }\end{array}$ & 8,7 & 86,9 & 4,3 & 5,9 & 76,5 & 17,6 & 13,3 & 80 & 6,7 \\
\hline $\begin{array}{l}6 \text { - Interatividades } \\
\text { entre alunos e } \\
\text { professores }\end{array}$ & 21,7 & 65,2 & 13 & 5,9 & 88,2 & 5,9 & 15,4 & 53,9 & 30,8 \\
\hline $\begin{array}{l}7 \text { - Interatividade } \\
\text { entre alunos e } \\
\text { tutores }\end{array}$ & 30,4 & 56,5 & 13 & 23,5 & 70,6 & 5,9 & 28,6 & 57,2 & 14,3 \\
\hline $\begin{array}{l}8 \text { - Houve estimulo } \\
\text { para interação entre } \\
\text { os alunos }\end{array}$ & 26,1 & 47,8 & 26,1 & 17,6 & 76,4 & 5,9 & 33.3 & 52,4 & 13,3 \\
\hline $\begin{array}{l}9 \text { - Houve uso de } \\
\text { recursos }\end{array}$ & 34,8 & 56,5 & 8,7 & 5,9 & 82,4 & 11,8 & 33,3 & 66,7 & 0 \\
\hline
\end{tabular}




\begin{tabular}{|c|c|c|c|c|c|c|c|c|c|}
\hline $\begin{array}{l}\text { tecnológicos fora do } \\
\text { MOODLE }\end{array}$ & & & & & & & & & \\
\hline $\begin{array}{l}10 \text { - Facilidade na } \\
\text { forma de } \\
\text { organização dos } \\
\text { conteúdos }\end{array}$ & 52,2 & 47,8 & 0 & 29,4 & 70,5 & 0 & 28,6 & 57,1 & 14,3 \\
\hline $\begin{array}{l}11 \text { - Razoável a quan- } \\
\text { tidade de recursos } \\
\text { usados em aula }\end{array}$ & 0 & 65,2 & 34,8 & 0 & 65,7 & 35,3 & 13,3 & 66,7 & 20 \\
\hline $\begin{array}{l}12 \text { - Os recursos } \\
\text { apresentados } \\
\text { despertam seus } \\
\text { interesses }\end{array}$ & 30,4 & 65,2 & 4,3 & 35,3 & 68,8 & 5,9 & 20 & 80 & 0 \\
\hline $\begin{array}{l}13 \text { - Adequação das } \\
\text { atividades } \\
\text { pedagógicas com o } \\
\text { conteúdo }\end{array}$ & 54,5 & 45,5 & 0 & 23,5 & 76,5 & 0 & 26,7 & 73,3 & 0 \\
\hline $\begin{array}{l}14 \text { - Coerência entre } \\
\text { os conteúdos e a } \\
\text { bibliografia }\end{array}$ & 63,6 & 31,8 & 4,5 & 52,9 & 47,1 & 0 & 51 & 49 & 0 \\
\hline
\end{tabular}

Fonte: Elaborado pelos autores com base nas respostas dos alunos dos cursos estudados.

De acordo com os dados apresentados na tabela 2, verificou-se principalmente que:

- Três questões investigadas (números: 12, 13 e 14) foram avaliadas positivamente por $47,5 \%$ dos alunos de ELE, $64,1 \%$ dos alunos de INF e $67,4 \%$ dos alunos de MA, destacando especialmente a coerência entre os conteúdos e a bibliografia. Também, pode-se considerar que a questão sobre as atividades pedagógicas tem isso bem aceito pelos alunos, indicando que as estratégias metodológicas escolhidas e a utilização dos recursos digitais dentro do AVA pelos professores e tutores, têm sido feitas com a preocupação e cuidado que um curso a distância requer, principalmente no que se refere ao processo de interação.

- Sobre o processo de interação, ou interatividade, verificou-se que 50,7\% dos alunos de ELE, 77,4\% dos alunos de INF e 42,2\% dos alunos de MA a percebem bem no ambiente virtual, sobretudo em relação à interatividade entre alunos e tutores e alunos e alunos. Porém, a interatividade entre alunos e professores foi avaliada positivamente entre os alunos dos cursos de Informática para Internet e Eletroeletrônica, em que apenas 13\% e 5,9\% afirmaram nunca haver interatividade, diferentemente do que foi percebido entre os alunos de Meio Ambiente.

- As respostas obtidas na questão um é uma incoerência em relação às respostas das questões dois e 10, pois, por exemplo, ao mesmo tempo em que a média de $75 \%$ dos alunos dos cursos avaliaram positivamente a clareza e a organização dos 
conteúdos, a maioria $68,5 \%$ desses mesmos alunos declara ter dificuldades em acesso aos conteúdos.

- Em relação à dificuldade sobre os conteúdos, questão três, foi unânime para os três cursos. Nos cursos de ELE e MA, a minoria (26,1\% e 1\%, respectivamente) declarou que nunca teve dificuldades (está de acordo com suas respostas da questão quatro: em que a maioria, 78,3\% e 93,4 respectivamente, afirmou possuir conhecimentos prévios sobre os conteúdos).

- Sobre a questão nove (uso de recursos tecnológicos fora do MOODLE), 56,5\% dos alunos de ELE, 82,4\% dos alunos de INF e 66,7\% dos alunos de MA, avaliaram positivamente o uso de recursos.

Além das questões apresentadas na tabela 2, foram verificados junto aos alunos quais os recursos existentes no MOODLE que os motivam mais durante seus estudos. A maioria dos alunos dos três cursos (70,9\% dos alunos de ELE, 77,7\% dos alunos de INF e $78,2 \%$ dos alunos de MA) declarou que os recursos que os mais motivam, na sequência de prioridades são: apresentação de texto com vídeo, vídeo e atividades. Texto com atividades, fóruns e debates e por último só texto.

Acredita-se que as respostas dos alunos precisam ser observadas com cuidado e atenção por parte dos professores, tutores, coordenadores de curso e coordenação geral, pois essas respostas representam um poderoso instrumento de feedback por parte dos alunos sobre as metodologias empregadas. Elas devem ser analisadas e avaliadas, de tal forma que as partes positivas possam ser reforçadas e as falhas corrigidas.

\section{Considerações finais}

Foi possível observar que as 14 disciplinas analisadas apresentaram relativa diversidade de tipos de recursos didáticos utilizados no ambiente, não se percebendo padronização do ponto de vista de uma metodologia de desenvolvimento das atividades das disciplinas. Pode-se inferir que o professor se baseia muito nas suas experiências didáticas oriundas do ensino presencial, adaptando-as ao ambiente virtual. Contudo, é importante ressaltar a necessidade de preparar materiais com boa qualidade visual dos 
recursos e conteúdos, que sejam objetivos, claros e agradáveis, o que poderia favorecer as atividades acadêmicas dos alunos.

Outro aspecto contemplado foi o estudo da forma como foram organizados e estruturados os materiais didáticos à luz da metodologia recursiva, tendo como parâmetros a forma como a metodologia se apresenta e os critérios que propõe. Desse modo, foi construído um olhar sobre o trabalho dos professores, sendo feitas observações e comparações com a metodologia para ver se os critérios utilizados pelos professores na construção dos materiais se enquadravam em alguma perspectiva metodológica.

A metodologia recursiva enfatiza a necessidade de cuidado especial do professor na avaliação dos conceitos a serem trabalhados nas aulas a partir da análise de prérequisitos e conceitos estruturantes dos conteúdos, adotando-se um processo recursivo na construção da proposta didática de apresentação dos conteúdos. Diante disso, constatou-se que os materiais didáticos apresentados dos cursos, não tinham clareza quanto a essa percepção, ou seja, quanto à organização dos pré-requisitos, conceitos estruturantes, à identificação e à reconstrução de conhecimentos. Especificamente, no que diz respeito aos conceitos estruturantes, os professores não trabalharam os conceitos relativos aos conteúdos, ou seja, se os conteúdos possuíam um encadeamento, uma organização, um planejamento dos conceitos estruturantes do conhecimento a ser adquirido.

Em relação à investigação dos métodos utilizados na produção de materiais didáticos produzidos nos cursos, pode-se afirmar que há uma preocupação relevante dos professores quanto ao desenvolvimento de conteúdos adequados à aprendizagem dos alunos, com a interatividade, com os recursos motivacionais e com a adequação das atividades pedagógicas. Contudo, constataram-se divergências entre as respostas dos professores e o trabalho de fato realizado na estruturação dos conteúdos das disciplinas no MOODLE.

O professor precisa refletir sobre sua prática pedagógica, lembrando que os princípios interacionistas devem se constituir como base para o preparo de suas aulas. Assim, o material didático precisa ser dinâmico, composto de diferentes estratégias de estudo e seguindo metodologias que estimulem e motivem a aprendizagem, permitindo 
que a construção do conhecimento pelo aluno ocorra a partir de interações autônomas e diversificadas.

Além disso, percebeu-se que os professores, tutores e gestores devem buscar uma formação mais adequada tendo em vista metodologias para desenvolvimento de materiais didáticos destinados especificamente a EaD.

\section{Referências}

BELISÁRIO, A. O material didático na educação a distância e a constituição de propostas interativas. In SILVA, M (Org). Educação online: teorias, práticas, legislação, formação corporativa. São Paulo: Edições Loyola, 2003.

BRASIL. Ministério da Educação. Decreto de Lei N².494, de 10 de fev. de 1998.

Regulamenta o art. 80 da lei 9394/96, referente à educação a distância. Brasília, DF, 1998. Disponível em: < http://portal.mec.gov.br/seed/arquivos/pdf/tvescola/leis/D2494.pdf >.

Acesso em: 30 set. 2014.

BRASIL. Ministério da Educação. Decreto de Lei №.5.622, de 19 de dez. 2005.

Regulamenta o art. 80 da lei 9394/96, que caracteriza a educação a distância. Brasília, DF, 2005. Disponível em: <http://www.planalto.gov.br/ccivil_03/_ato2004-

2006/2005/Decreto/D5622.htm>. Acesso em: 30 set. 2014.

BRASIL. Ministério da Educação. Decreto de Lei Nº.6.301, de 12 de dez. de 2007. Institui o Sistema Escola Técnica Aberta do Brasil. Brasília, DF, 2007. Disponível em: <http://www.planalto.gov.br/ccivil_03/_Ato2007-2010/2007/Decreto/D6301.htm>. Acesso em: 30 set. 2014 .

BRASIL. Ministério da Educação. Decreto de Lei №.7.589, de 26 de outubro de 2011. Institui a Rede e-Tec Brasil. Brasília, DF, 2011. Disponível em:

<http://www.planalto.gov.br/ccivil_03/_At02011-2014/2011/Decreto/D7589.htm>. Acesso em: 30 set. 2014 .

BRASIL. Ministério da Educação. Lei № 9.394, de 20 de dezembro de 1996. Estabelece as diretrizes e bases da educação nacional. Brasília, DF, 1996. Disponível em:

<http://www.planalto.gov.br/CCIVIL/leis/L9394.htm>. Acesso em: 30 set. 2014.

CENSO EAD. BR .Organização Anuário Brasileiro Estatístico de Educação Aberta e a Distância, 2013/2014. São Paulo: Instituto Monitor, 2014.

CONSELHO NACIONAL DE EDUCAÇÃO (CNE). Parecer n. 16, de 5 de outubro de 1999.

Diretrizes Curriculares Nacionais para a Educação Profissional de Nível Técnico. Brasília, 
DF, 1999. Disponível em: <http://www.mec.gov.br/cne/parecer.shtm>. Acesso em: 30 set. 2014.

FORMIGA, M. A terminologia da EAD. In: LITTO, Fredric Michael e FORMIGA, Marcos (Orgs). Educação a Distância: o Estado da Arte. São Paulo: Pearson Education, 2009.

GARCIA, Rolando. O conhecimento em construção. Das formulações de Jean Piaget à teoria de sistemas complexos. Porto Alegre: Artmed, 2002.

LÉVY, Pierre. A máquina universo. Porto Alegre: ArtMed, 1987.

NEDER, Maria Lúcia Cavalli. Produção de material didático para educação a distância. Curso: Formação de Professores para Educação a Distância. Fevereiro de 2005. Disponível em: <http://www.ead.ufsc.br/ambiente/mod/resource/view.php?id=126>. Acesso em: 20 set. 2014 .

OLIVEIRA, Celina Couto; COSTA, José Wilson da; MOREIRA, Mércia. Ambientes Informatizados de aprendizagem. Campinas: Papirus, 2001.

PIAGET, Jean. A Epistelomogia Genética; Sabedoria e Ilusões da Filosofia; Problemas de Psicologia Genética. In.: Piaget. Traduções de Nathanael C. Caixeiro, Zilda A. Daeir, Celia E.A. Di Pietro. São Paulo: Abril Cultural, 1978. 426p. (Os Pensadores).

THOMPSON, Bruce. Guia prático para o desenvolvimento de projetos em EaD). Instituto Nacional de Educação a Distância. The Commonwealth of Learning. Vancouver, CA, 2002.

VIDAL, Elisabete. Ensino a distância versus ensino tradicional. Porto: Universidade Fernando Pessoa, 2002.

Universidade do Estado de Santa Catarina - UDESC Programa de Pós-Graduação em Educação - PPGE Revista Linhas Volume 18 - Número 36 - Ano 2017 revistalinhas@gmail.com 